\title{
Theileria annae (syn. Babesia microti-like) infection in dogs in NW Spain detected using direct and indirect diagnostic techniques: clinical report of
} 75 cases

Guadalupe Miró ${ }^{*}$, Rocío Checa ${ }^{1}$, Andrea Paparini ${ }^{2}$, Nieves Ortega ${ }^{1}$, José Luís González-Fraga ${ }^{3}$, Alex Gofton², Adrián Bartolomé ${ }^{4}$, Ana Montoya ${ }^{1}$, Rosa Gálvez ${ }^{1}$, Pedro Pablo Mayo ${ }^{5}$ and Peter Irwin²

\begin{abstract}
Background: In north-western Spain, piroplamosis caused by Theileria annae is now recognized as a serious problem because veterinarians, despite being aware of the clinical signs of piroplasmosis, lack the necessary information on its epidemiology or specific diagnostic tools for its management. This, along with the fact that $T$. annae infection is also refractory to current piroplamosis treatments, prompted this study designed to assess the clinical presentation and diagnosis of this largely unknown parasitic disease in dogs.
\end{abstract}

Methods: One hundred and twenty dogs in NW Spain suspected clinically of having piroplasmosis were examined and piroplasm species detected by light microscopy (LM) observation of Giemsa-stained blood smears, immunofluorescent antibody test (IFAT), and PCR plus sequencing.

Results: Seventy five of the sick dogs were confirmed to be infected with T. annae by PCR (designated "true infection cases"). Intraerythrocytic ring-shaped bodies morphologically compatible with small piroplasms were observed by $L M$ in 59 (57 true infections) of the 120 blood samples. Anti-Babesia antibodies were detected by IFAT in 59 of the 120 sera (55 of which were "true infections"). Using PCR as the reference method, moderate agreement was observed between positive LM vs PCR and IFAT vs PCR results (kappa values: 0.6680 and 0.6017 , respectively). Microscopy examination and IFAT were moderately sensitive in detecting the pathogen (76\% and $73.3 \%$, respectively). In the 75 cases of "true infection", the most common clinical signs observed were pale mucous membranes, anorexia and apathy. Blood cell counts consistently revealed severe regenerative anaemia and thrombocytopenia in dogs with piroplasmosis due to $T$. annae. Young dogs ( $\leq 3$ year) $(p=0.0001)$ were more susceptible to the disease.

Conclusion: Microscopy showed moderate diagnostic sensitivity for acute T. annae infection while IFAT-determined antibody titres were low (1/64 to 1/128). The infecting species should be therefore confirmed by molecular tests. Our results suggest that the disease affects dogs in regions of Spain bordering the endemic Galicia area where this piroplasm has not been previously reported (Asturias, northern Spain). Further epidemiological surveys based on serological and molecular methods are required to establish the current geographical range of $T$. annae infection.

Keywords: Theileria annae, Babesia microti-like, Canine piroplasmosis, Tick-borne diseases, Dog, IFAT, PCR

\footnotetext{
* Correspondence: gmiro@ucm.es

1 Department of Animal Health, Veterinary Faculty, Universidad Complutense de Madrid, Madrid, Spain

Full list of author information is available at the end of the article
} 


\section{Background}

Theileria annae (syn. Babesia microti-like) is a recently recognized piroplasm that causes canine piroplasmosis along with other species of the genera Theileria and Babesia [1,2].

Historically, Babesia infection in dogs was identified according to the morphologic appearance of the parasite in the erythrocyte. Based on relative size, these parasites are broadly divided into two groups, large and small piroplasms. Although all large forms reported to date have been ascribed to the genus Babesia, small Babesia spp. and Theileria spp. cannot be distinguished by microscopy and DNA-based molecular techniques are required for an accurate identification [3,4]. Indeed, it is currently unclear if the protozoan $T$. annae is a member of the genus Theileria or Babesia [2,5]. No evidence was initially presented [2] for extra-erythrocytic infecting stages or for the absence of transovarial transmission in ticks (distinguishing features of Theileria spp.). Morphologically, T. annae resembles small piroplasms such as Babesia gibsoni which, phylogenetically, is considered a "true babesia". Molecularly, however, it appears to be closer to the genetically-distinct rodent piroplasm $B$. microti (B. microti group) and only distantly related to "true theilerias" such as Theileria parva [2,6,7].

At present, 12 piroplasm species have been reported in dogs worldwide but some of these have been only detected by molecular techniques [1]. Four species have been described in Europe: Babesia canis, Babesia vogeli, B. gibsoni and T. annae.

Babesia canis is endemic in temperate regions and is the most common species reported in Europe (northern Spain, Portugal, France, central Europe and Eastern Europe). Babesia vogeli and B. gibsoni are widely distributed across both Old and New World continents [8,9]. In Europe, $B$. vogeli has been described in the Mediterranean basin, whereas $B$. gibsoni only occasionally appears in Europe [10], mainly as the consequence of introduced infected dogs from endemic areas (Asia, United States and Australia) [8].

Studies in the United States and Australia have indicated that direct dog to dog transmission (in American Pit bull terriers and other fighting dogs) is likely and this could be the main mode of transmission outside Asia for B. gibsoni $[11,12]$.

T. annae was first described in 2000 in a dog from Germany that had travelled to the Pyrenees [2]. Today, the infection is considered endemic in NW Spain (Galicia) [5,13]. Using molecular techniques T. annae has been also detected in Spanish regions outside Galicia, such as Barcelona [14], and in other countries including NW Portugal [15], Croatia [16], US [12] and Sweden [17]. However, in most cases the travel history of the dogs was unknown. Other authors have reported cases of T. annae infecting foxes in Spain [18], Portugal [19], Italy [20], Croatia [21], Canada [22] and the US [23]. Among all piroplasm species reported in Europe, $T$. annae seems to show the greatest preference for foxes. Thus, $T$. annae has been detected in red foxes in Spain and Portugal at prevalences from $14 \%$ to $69.2 \%$, respectively; while $B$. canis has been only occasionally identified in these animals [19]. To date, there are no available data regarding clinical impacts on foxes.

The transmission vector of $T$. annae is presently unknown. Ixodes hexagonus has been proposed as a likely candidate because endemic areas of $T$. annae infection closely match its distribution range [18,24]. However, $T$. annae DNA has been observed in both $I$. hexagonus and I. ricinus, though no data exist to substantiate their competence as vectors for $T$. annae.

T. annae-infected dogs show severe clinical signs and clinicopathological abnormalities resembling those of other piroplasm infections such as fever, pale mucous membranes or haemoglobinuria [25]. Despite morphologic differences, T. annae is often ascribed by veterinarians to other Babesia spp. mainly B. canis. Currently, there are no diagnostic tools to distinguish between the different piroplasms in routine veterinary practice and their detection by microscopy in red blood cells is still the only method available to practitioners. In laboratory settings, the immunofluorescent antibody test (IFAT) is the most widely used test for a serology diagnosis and is considered highly sensitive and moderately specific to detect chronic infection and subclinical infection in carriers $[4,26,27]$. The polymerase chain reaction (PCR) is a sensitive and specific diagnostic test widely employed to diagnose canine babesiosis. When PCR is combined with sequencing, species-specific primers/ probes, or restriction fragment length polymorphism (RFLP) analysis it can be used to detect infected dogs with low parasitaemia levels and to identify parasites $[12,28,29]$. However, the literature lacks widespread serological and/or molecular surveys of $T$. annae infection. Similarly, comparative methodological studies on the available diagnostic procedures are limited.

The present study was designed to examine the clinical picture of $T$. annae infection in dogs in NW Spain and assess how best to diagnose this largely unknown disease.

\section{Methods}

\section{Sample and data collection}

Over the period June 2012 to January 2014, dogs from several Veterinary Clinics in NW Spain were tested for Theileria annae. Inclusion criteria for the enrolment of dogs were clinical signs suggestive of piroplasmosis such as: pale mucous membranes, apathy, anorexia, orangey faeces, fever, weight loss, or haematuria. In all dogs the presence of 
large piroplasms (B. canis or B. vogeli) was first ruled out via microscopy by collaborating practitioners.

All participating dogs were subjected to a clinical examination and blood collection. From each dog, a $4.5 \mathrm{ml}$ blood sample was obtained by cephalic venipuncture and $1.5 \mathrm{ml}$ of the collected blood placed in two EDTA tubes: a $1 \mathrm{ml}$ tube used for full blood counts and blood smears; and a $0.5 \mathrm{ml}$ tube used to detect $T$. annae by genomic DNA isolation, PCR and sequencing. Also, $3 \mathrm{ml}$ of the collected blood samples were placed in tubes without anticoagulant for biochemical profiles and antibody testing. All blood samples were kept at $4^{\circ} \mathrm{C}$ until processing.

In the clinical file, we recorded the: identification number, age, breed, sex, weight, rural or urban living environment and travel history. Also considered were the clinical history and the specific clinical signs at the time of sampling such as changes in the colour of mucous membranes, anorexia, haematuria, fever, weight loss, splenomegaly, hepatomegaly, or lymphadenomegaly.

\section{Haematology and biochemistry}

The following variables were determined using an automated blood analyser (Sysmex XT-2000i, Roche Diagnostics, Spain): red-blood-cell count (RBCC), reticulocyte count, haemoglobin concentration, haematocrit, red cell distribution width (RDW), mean corpuscular volume $(\mathrm{MCV})$, mean corpuscular haemoglobin $(\mathrm{MCH})$, mean corpuscular haemoglobin concentration (MCHC), leukocyte and platelet count. Differential white blood cell counts were conducted by conventional microscopy procedures. A clinical biochemical analyser (Cobas integra ${ }^{\circ} 400$ plus, Roche Diagnostics, Spain) was used for serum concentrations of glucose, total protein, albumin, globulin, urea and creatinine; aspartate aminotransferase (AST) activity, alanine aminotransferase (ALT) activity, glutamyltransferase (GGT) activity, creatinine kinase (CK), alkaline phosphatase (ALP) activity and total, direct and indirect bilirubin concentrations. All tests were performed using standard techniques. Platelet numbers and hepatic enzyme activities could not always be determined due to platelet aggregation or haemolysis.

\section{Microscopic detection of the parasite}

Giemsa-stained thin blood smears were examined by light microscopy (LM) to detect small intraerythrocyte ring-shaped bodies compatible with $T$. annae. The smears were air dried, fixed in absolute methanol for 5 min, stained using 20\% Giemsa and then observed using a $1000 \times$ magnification objective under immersion oil. All samples were examined by the same technician.

\section{Serum antibodies}

Anti-Babesia antibodies were detected by the immunofluorescent antibody test (IFAT) using a commercially available antigen kit (MegaScreen ${ }^{\bullet}$ FLUO BABESIA microti, Austria). Fixed erythrocytes infected with Babesia microti were used as antigen. The IFAT was performed according to the manufacturer's instructions using a cutoff $=1: 64$ to denote seropositivity. Positive sera were further tested in a serial dilution series (from1:32). Slides were examined by the same reader under a fluorescence microscope.

Serological testing for the most prevalent CVBD present in Spain [30], Leishmania infantum and Ehrlichia canis, was also performed by IFAT.

In the L. infantum test, specific antibodies were detected against in-house cultured promastigotes and antiLeishmania-specific immunoglobulin G (IgG) antibodies were detected as described previously [31] using a cutoff $=1: 100$ to denote seropositivity. The serial dilutions prepared were $1 / 25,1 / 50,1 / 100,1 / 200,1 / 400,1 / 800$ and $1 / 1600$.

IFAT for anti-E. canis antibodies was only performed in 75 dogs in which T. annae was PCR confirmed. For this test, a local strain was used as antigen and a cut-off $=1: 80$ was taken to denote seropositivity.

\section{DNA isolation and PCR-RFLP}

Genomic DNA was isolated from peripheral whole blood $(100 \mu \mathrm{l})$ using the QIAamp ${ }^{\oplus}$ DNA blood micro kit (QIA$\left.\mathrm{GEN}^{\circ}, \mathrm{USA}\right)$ as described by the manufacturer. The extracted DNA was eluted in molecular-grade water $(70 \mu \mathrm{l})$ and stored at $-20^{\circ} \mathrm{C}$ until further use. DNA quality was quantified fluorometrically using the Qubit ${ }^{\circ}$ system (Life Technologies, USA). Blood-DNA was screened for piroplasms using PCR-based assays targeting the small subunit ribosomal RNA gene ( $18 \mathrm{~S}$ rDNA). The implemented assays included a shorter nested PCR (850 bp; primers BT F1/R1 followed by BT F2/R2) [28].

PCR products were run on a $1 \%$ agarose gel containing SYBR Safe Gel Stain (Invitrogen, USA), and visualized with a dark reader trans-illuminator (Clare Chemical, USA). PCR products corresponding to the expected length were excised, and sequenced using an ABI Prism Terminator Cycle Sequencing kit (Applied Biosystems, USA) in an Applied Biosystem 3730 DNA Analyzer.

\section{Phylogenetic analysis}

Phylogenetic analysis was conducted on the sequences obtained during the present study and additional piroplasms sequences available in GenBank.

Sequence chromatogram files were analyzed by FinchTV 1.4 (http://www.geospiza.com), and imported into Geneious Pro V. 7.1.5 (Biomatters, Auckland, NZ), for editing, assembly and alignments. Alignments obtained by MAFFT v7.017 [32] and MUSCLE [33] were trimmed manually and trees were reconstructed using the Geneious FastTree plugin [34]. When applicable, 
alignments were curated by Gblocks [35], remotely [36] with the low-stringency set of options selected. Cardiosporidium cionae was used as an outgroup based on previous recommendations [37].

\section{Tick collection and identification}

Ticks were obtained from dogs observed to have ticks in the clinical examination and stored in $70 \%$ ethanol for identification to species level, sexing and staging using morphological keys [38].

\section{Statistical analysis}

Results were analysed using the statistics package SAS version 9.4. IFAT and microscopy results were compared with molecular results using McNemar's test, simple Kappa coefficient and Wilcoxon scores (Rank Sums). PCR and sequencing was used as the gold standard reference method to identify small piroplasms [29,39]. Sensitivity and specificity are provided for each of the techniques used. Sensitivity was calculated as the number of LM or IFAT positive results divided by the number of PCR positive results, and specificity as the number of LM or IFAT negative results divided by the total number of PCR negative results. According to the central limit theorem, our sample was sufficiently large $(\mathrm{N}>30)$ for the use of parametric tests. Relationships between $T$. annae infection and the remaining categorical variables were assessed using the Chi-squared test and between $T$. annae infection and continuous variables by the Student t-test. Significance was set at $p \leq 0.05$.

\section{Results}

\section{Molecular diagnosis}

Inclusion criteria for this study were met by 120 dogs. In 75 of these dogs (62.5\%), T. annae infection was confirmed by PCR and sequencing, these animals are hereafter referred to as "true cases of T. annae infection". In 15 of the dogs enrolled, Babesia gibsoni was PCRdetected in 3 and B. canis in 12.

When we compared our 75 sequencing results with existing GenBank entries, the sequences obtained were identified as $T$. annae in BLAST searches. All the sequences obtained were above $98 \%$ identical to $T$. annae. Several iterative bioinformatics steps were implemented for careful validation of the input data. Inclusion in the final subset used for the phylogenetic reconstruction was based on chromatogram quality, length, specificity and position of the sequence within the alignment. After a preliminary selection, 43 sequences with lengths ranging from 231 to 770 bp (Mean: 617.7; Std Dev: 125.4) were processed further. BLAST-searches returned hits for canine piroplasms and members of the B. microti group. After trimming, two un-curated alignments were obtained and used for the phylogenetic reconstructions (575 bp, 93 sequences, $83.9 \%$ pairwise identity and $223 \mathrm{bp}, 104$ sequences, $91.8 \%$ pairwise identity). In particular, while the shorter alignment included all the sequences from the present study, in the longer only the longest sequences were retained. Regardless of the alignment length and implementation of the optional curation step (by Gblocks), all sequences obtained during the present study clearly grouped with either canine babesias (e.g., B. canis, B. gibsoni) or within the B. microti group (e.g., T. annae isolate Dog\#8, Acc. No. JX454779).

\section{Microscopy and serology results related to PCR results}

The results obtained for the three diagnostic techniques employed are provided in Figure 1. Intraerythrocytic ringshaped bodies, morphologically compatible with small piroplasms (Figure 2) were detected by LM in 59 of the 120 blood samples (49.2\%), two of which were confirmed as false positives. In one of these false positives, no piroplasm DNA was detected by PCR while the other case was sequenced as B. canis.

Anti-Babesia antibodies were detected by IFAT in 59 of the 120 dogs (49.2\%), four of which were confirmed as false positives. In two of these, no piroplasm DNA was detected and in the remaining two, the presence of $B$. canis was observed. Antibody titres were $1 / 64$ to $1 / 1024$ and distributed as follows: $1 / 64(\mathrm{n}=27), 1 / 128(\mathrm{n}=17), 1 / 256$ $(\mathrm{n}=4), 1 / 512(\mathrm{n}=3), 1 / 1024(\mathrm{n}=5)$, and 1/2048 $(\mathrm{n}=3)$.

We observed good agreement between a positive LM and PCR result, and between a positive IFAT and PCR result (Tables 1 and 2). Kappa values indicated moderate agreement in both cases (0.6680 and 0.6017 , respectively) though better agreement was observed between LM and PCR than between IFAT and PCR. Sensitivities and specificities were $76 \%$ and $95.6 \%$ for LM and $77.3 \%$ and $91.1 \%$ for IFAT, respectively

When comparing the use of LM plus IFAT versus PCR, a greater sensitivity was observed (85.33\%) than if we used either technique on its own. However, specificity was reduced (86.66) (Table 3).

A greater number of positive PCR results was detected in samples testing LM- or IFAT negative, than negative PCR results in samples testing LM- or IFAT positive. The McNemar test indicated these were not chance discrepancies meaning that false negatives were more likely than false positives for LM $(p=0.0003)$ and IFAT $(p=0.0011)$ compared to PCR for a diagnosis of T. annae.

According to the Wilcoxon rank sum test, antibody titres and PCR results were positively correlated $(\mathrm{p}=0.03)$ such that high antibody titres were associated with the presence of parasite DNA in the blood.

\section{Vector-borne diseases serology testing}

Anti- $L$. infantum antibodies were detected by IFAT in 13 of the 120 dogs (10.8\%). Nine of these animals (9/13) 


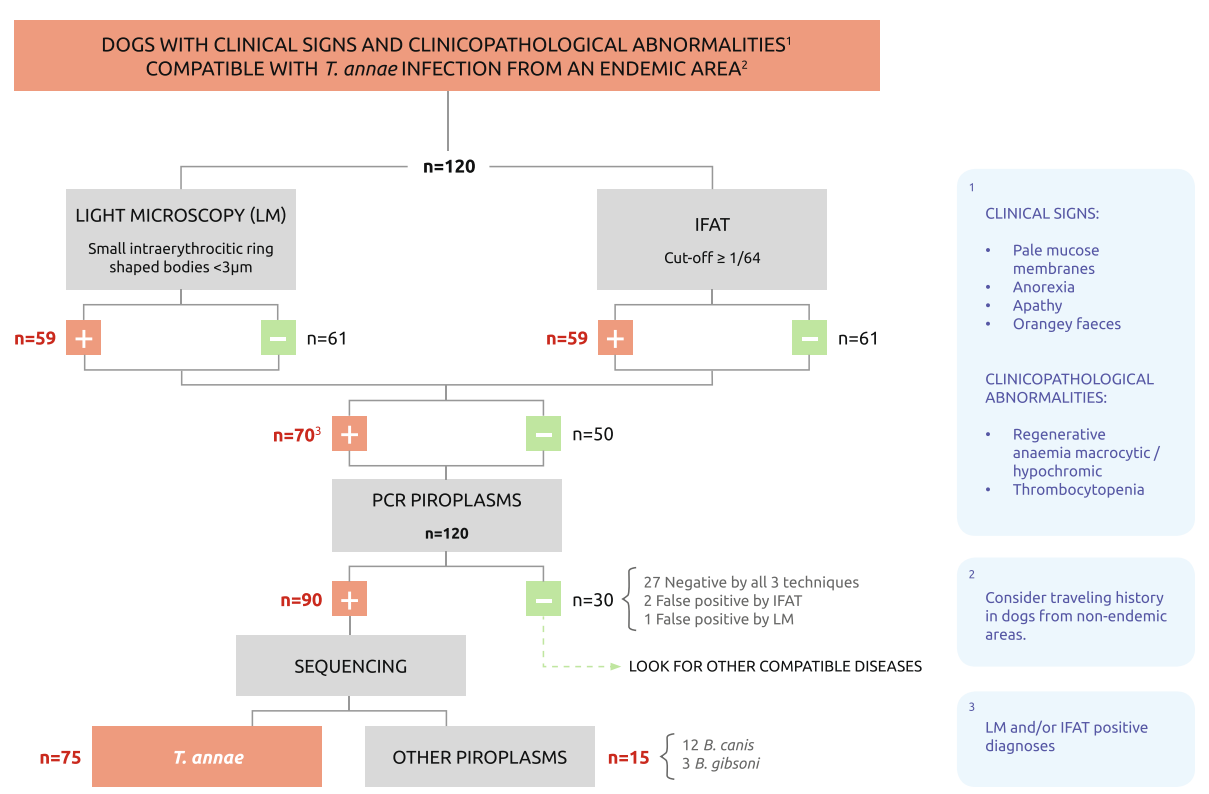

Figure 1 Decision tree for the diagnostic approach to dogs with suspected clinical signs and/or clinicopathological abnormalities consistent with $T$. annae infection. Abbreviations: IFAT = immunofluorescence antibody test, $L M=$ light microscopy, PCR = polymerase chain reaction.

were scored positive for T. annae by PCR, yet antibody titres were low (1/100 in 5 dogs and $1 / 200$ in 4 dogs). A further three of these dogs (3/13) tested PCR positive for other piroplasm species and antibody titres were also low $(1 / 200$ in 2 dogs with B. canis and $1 / 100$ in $1 \mathrm{dog}$ with B. gibsoni). These animals showed no clinical or other signs of leishmaniosis (e.g., lymphadenomegaly, cutaneous lesions, hypergammaglobulinaemia, hypoalbuminaemia). In the remaining dog showing anti- $L$. infantum antibodies (1/13), T. annae was not detected and clinical signs were compatible with canine leishmaniosis. In this animal the antibody titre was $1 / 400$.

Anti-E. canis antibodies were not detected by IFAT in any of the 75 true infection cases.

\section{Clinical picture}

In this section, we describe the clinical picture observed in the 75 dogs confirmed by PCR to be infected by $T$. annae.

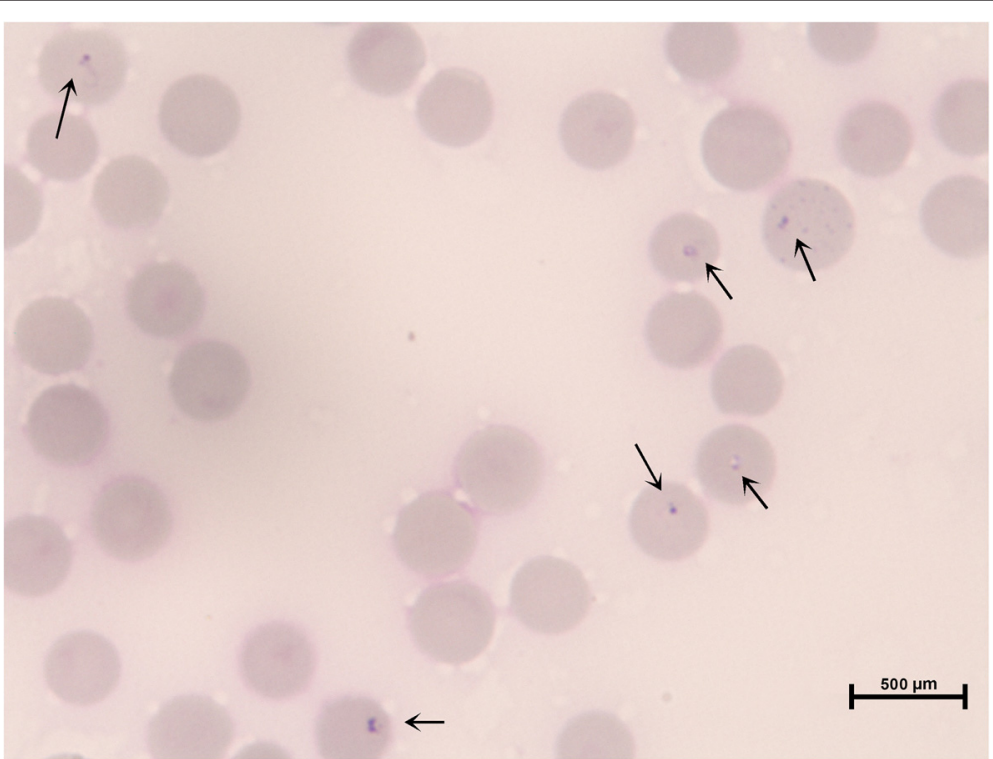

Figure 2 Intraerythrocytic ring-shaped bodies, morphologically compatible with $T$. annae. Giemsa stained blood smear ( $x 1000)$. 
Table 1 Correlation between LM and PCR used to detect T. annae infection

\begin{tabular}{lllll}
\hline & & \multicolumn{2}{l}{ PCR } & \\
\cline { 3 - 4 } & & Negative & Positive & Total \\
\hline LM & NEGATIVE & 43 & 18 & 61 \\
& POSITIVE & 2 & 57 & 59 \\
& TOTAL & 45 & 75 & 120
\end{tabular}

Kappa 0.6680 , specificity $95.56 \%$, sensitivity $76 \%$, positive predictive values (PPV) $96.61 \%$, negative predictive values (NPV) $70.49 \%$.

The main reasons for a visit to the veterinarian were apathy (51.4\%), loss of appetite (41.6\%) and weakness (19.4\%). The most prevalent clinical signs observed in the physical examination were pale mucous membranes (69.9\%), anorexia (73.9\%) and apathy (66.6\%). Other reported clinical signs were orangey faeces (12.5\%), vomiting $(5.5 \%)$, tachycardia (13.8\%), fever (29.6\%), weight loss (11.7\%), haematuria (18.5\%) and splenomegaly (25\%). Significant differences between T.annae-infected and noninfected dogs were detected in the clinical signs pale mucous membranes $(p=0.0147)$, anorexia $(p=0.0374)$ and orangey faeces $(\mathrm{p}=0.02)$.

The main haematological finding was regenerative anaemia in 79.6\% (57/72) and non-regenerative anaemia in $6.9 \%$. Most sick dogs had mild to severe anaemia, $80 \%$ showing less than $4.2 \times 10^{6}$ erythrocytes $/ \mathrm{ml}, 12.2 \mathrm{~g}$ haemoglobin/dl and 33\% haematocrit. Anaemia was most often hypochromic and macrocytic. Median red blood cell counts, haemoglobin concentrations and haematocrits in infected dogs were clearly lower compared to reference values or corresponding values for the group of non-infected dogs. In addition, MCV values were significantly higher and $\mathrm{MCHC}$ values were significantly lower in infected compared to non-infected dogs (Table 4).

The second most frequent haematological abnormality was thrombocytopenia (58.3\%). Leukocyte counts were elevated in 18 out of 72 infected dogs (mostly with neutrophilia) and diminished in 5. Eosinopenia was observed in 23 out of 68 infected dogs. The main biochemical abnormalities detected were hyperglobulinaemia (33/65) and elevated hepatic enzyme activities (25/57). Azotaemia was observed in a few cases (7/71) yet differences were non-significant with respect to non-infected dogs.

Table 2 Correlation between IFAT and PCR used to detect T. annae infection

\begin{tabular}{lllll}
\hline & & \multicolumn{2}{l}{ PCR } & \\
\cline { 3 - 4 } & & Negative & Positive & Total \\
\hline IFAT & NEGATIVE & 41 & 20 & 61 \\
& POSITIVE & 4 & 55 & 59 \\
& TOTAL & 45 & 75 & 120 \\
\hline
\end{tabular}

Kappa 0.6017 , specificity $91.11 \%$, sensitivity $73.33 \%$, positive predictive values (PPV) $93.22 \%$, negative predictive values (NPV) $67.21 \%$.
Table 3 Correlation between IFAT-LM and PCR used to detect $T$. annae infection

\begin{tabular}{lllll}
\hline & & \multicolumn{2}{l}{ PCR } & \\
\cline { 3 - 4 } & & Negative & Positive & Total \\
\hline LM \& IFAT & NEGATIVE & 39 & 6 & 50 \\
& POSITIVE & 11 & 64 & 70 \\
& TOTAL & 45 & 75 & 120 \\
\hline
\end{tabular}

Kappa 0.7043 , specificity $86.66 \%$, sensitivity $85.33 \%$, positive predictive values (PPV) $91.42 \%$, negative predictive values (NPV) $78 \%$.

\section{Epidemiological data}

Of the 120 dogs included in this study, 103 dogs were from Galicia, 73 of which tested positive for $T$. annae infection, and 17 dogs were from a neighbouring area (Asturias), two of which tested positive for the parasite (Figure 3). One of the two PCR-confirmed cases in Asturias had never left that area.

Epidemiological data compiled for the 75 confirmed $T$. annae cases are provided in Table 5. No differences emerged according to sex or breed. However, a greater number of positive cases (81.54\%) were recorded in dogs $\leq 3$ years $(\mathrm{p}=0.0001)$ compared to older dogs (46.8\%). Significant correlations were also noted between T. annae infection and a small or medium dog size $(\leq 22$ $\mathrm{Kg})(\mathrm{p}=0.0012)$ or being a hunting $\operatorname{dog}(\mathrm{p}=0.014)$.

In addition, higher percentages of $T$. annae positive dogs were recorded in dogs living in rural (66.6\%) than urban areas (45.8\%). There was no significant correlation between seasonality and T. annae infection. Further, $46.6 \%(35 / 75)$ of $T$. annae infected dogs were found to have ticks yet no significance was detected for this risk factor (data recorded during signalment). We collected 42 ticks from 22 dogs, 15 of which were true infection cases. These ticks were identified as Ixodes hexagonus (50\%), Ixodes ricinus (19\%), Dermacentor reticulatus (16\%), and Dermacentor marginatus (5\%). Only, four nymphs could be classified to the genus level as Ixodes spp.. Ixodes hexagonus was identified in 10 of the $15 T$. annae infected dogs.

\section{Discussion}

In this study, T. annae infection was assessed by PCR, LM and IFAT on blood and serum samples obtained from dogs in NW Spain suspected of having piroplasmosis.

Microscopy examination is the easiest and most accessible diagnostic test, requiring a well prepared and suitably stained blood smear together with a trained observer. Our results indicate the good specificity (95.56\%) and moderate sensitivity (76\%) of this procedure as well as its moderate agreement with PCR. However, it should be noted that we assume that most of the dogs examined here were in the clinical phase of $T$. annae infection when the visual detection of piroplasms is easier than in animals with low parasitaemia levels due to chronic 
Table 4 Descriptive statistics and comparative Student t-test for haematological variables recorded in T. annae infected $(n=75)$ and non-infected dogs $(n=45)$

\begin{tabular}{|c|c|c|c|c|c|c|c|c|}
\hline \multirow{2}{*}{$\begin{array}{l}\text { Blood variable (normality } \\
\text { reference range) }\end{array}$} & \multirow[t]{2}{*}{ Group } & \multirow[t]{2}{*}{$\mathbf{N}$} & \multirow[t]{2}{*}{ Mean } & \multirow[t]{2}{*}{ SD } & \multicolumn{3}{|c|}{ Percentiles } & \multirow[t]{2}{*}{$P$ value } \\
\hline & & & & & $25^{\text {th }}$ & $50^{\text {th }}$ & $75^{\text {th }}$ & \\
\hline \multirow[t]{2}{*}{ Erythrocytes $(5.50-8.50) \times 10^{6} / \mu \mathrm{l}$} & I & $72^{*}$ & 3.28 & 1.63 & 2.16 & 2.77 & 4.32 & $<0.0001$ \\
\hline & $\mathrm{Nl}$ & $38^{*}$ & 4.9 & 2.04 & 3.57 & 5.3 & 6.06 & \\
\hline \multirow[t]{2}{*}{ Haematocrit (37.00-55.0)\% } & । & 72 & 27.12 & 11.9 & 18.6 & 23.45 & 36.2 & 0.0019 \\
\hline & $\mathrm{NI}$ & 38 & 35.16 & 13.86 & 23.50 & 36.75 & 44.9 & \\
\hline \multirow[t]{2}{*}{ Haemoglobin $(12.00-18.00) \mathrm{g} / \mathrm{dl}$} & I & 72 & 7.75 & 3.75 & 5 & 6.5 & 10.2 & $<0.0001$ \\
\hline & $\mathrm{Nl}$ & 38 & 11.04 & 4.57 & 6.5 & 12 & 14.1 & \\
\hline \multirow[t]{2}{*}{ MCV (60.00-76.00)fl } & । & 72 & 82.84 & 8.25 & 76 & 81.5 & 83.3 & 0.0088 \\
\hline & $\mathrm{Nl}$ & 38 & 76.02 & 12.99 & 70.1 & 73 & 75.6 & \\
\hline \multirow[t]{2}{*}{ MCHC $(32.00-36.00) \mathrm{g} / \mathrm{dl}$} & । & 72 & 28.25 & 2.61 & 26.7 & 28.2 & 29.7 & $<0.0001$ \\
\hline & $\mathrm{Nl}$ & 38 & 31.2 & 3.12 & 29.5 & 31.2 & 32.7 & \\
\hline \multirow[t]{2}{*}{ MCH (19.5-24.5)pg } & I & 72 & 23.18 & 1.73 & 22.1 & 23.1 & 23.8 & 0.5552 \\
\hline & $\mathrm{Nl}$ & 38 & 23.59 & 4.08 & 22.1 & 23 & 23.8 & \\
\hline \multirow[t]{2}{*}{ RDW (14.00-20.25)\% } & 1 & 72 & 17.44 & 3.26 & 15.1 & 17.45 & 19.2 & 0.1385 \\
\hline & $\mathrm{NI}$ & 38 & 16.47 & 3.06 & 14.5 & 14.9 & 18.5 & \\
\hline \multirow[t]{2}{*}{ Leukocytes $(6.00-17.00) \times 10^{3} / \mu$} & । & 72 & 14.42 & 6.25 & 10.5 & 13.32 & 17.1 & 0.3649 \\
\hline & $\mathrm{Nl}$ & 38 & 12.64 & 11.3 & 7.89 & 10.84 & 14.54 & \\
\hline \multirow[t]{2}{*}{ Platelets $(200-500) \times 10^{3} / \mu \mathrm{l}$} & । & 59 & 158.5 & 90.35 & 90 & 165 & 218 & 0.019 \\
\hline & $\mathrm{Nl}$ & 33 & 211.2 & 121.25 & 150 & 212 & 272 & \\
\hline
\end{tabular}

*no data available for 3 infected and 7 non-infected dogs.

SD: standard deviation.

$\mathrm{I}=T$. annae infected dog; $\mathrm{NI}=T$. annae non-infected dogs.

disease [1]. In effect, LM has been described as less sensitive to detect chronic and sub-clinical piroplasmosis in carrier dogs [40].

We considered the molecular approach as the gold standard method for the diagnosis of small piroplasm infections. Accordingly, using the molecular diagnostic test, a larger number of positive dogs for $T$. annae infection were detected (62.5\%). Other PCR assays used to diagnose B. gibsoni infections have shown a high specificity and sensitivity $[29,41]$. In the latter studies, PCR was able to detect the parasite both at an earlier stage of infection than IFAT or LM and in the late stages of infection, when parasitaemia levels are low and Giemsa-stained thin blood smears return negative results [41]. Nevertheless, false negative PCR results have been reported in chronic babesiosis, attributed to parasite elimination from the circulating blood by the host [40]. This could determine that in the long term (up until 420 days post-infection) an infection might only be revealed (retrospectively) by serology [42].

In agreement with a previous report [43], we observed moderate agreement between our IFAT and PCR results. In contrast, discrepancies were reported by Kubelová et al. [44] for these techniques in endemic areas of canine piroplasmosis.
Serological cross-reactions between T. annae and B. canis were produced in two dogs. Cross reactions have been also reported between $B$. gibsoni and B. canis by other authors [45]. Most of the present dogs testing seropositive for $T$. annae $(\mathrm{n}=59)$ showed low antibody titres $(1 / 64$ or $1 / 128)$. Such titres reflect an early stage of infection. For B. canis, it has been described that the first detectable IgG antibodies usually appear 2-3 weeks after infection [46,47]. In addition, low antibody titres could be indicative of past infection or exposure and not necessarily of present infection. A serological diagnosis is therefore a more reliable method for the detection of hidden or past infections (i.e. chronically infected carrier dogs) though acute infections may not be accurately diagnosed if this technique is performed alone. This issue, however, needs confirmation owing to a lack of serological data. It has recently been argued that the diagnosis of infection by a vector-borne pathogen in dogs can be improved by running serological and PCR based tests in parallel [48]. However, we observed no benefits of the use of both techniques over that of PCR alone. Serology is unable to distinguish between $B$. canis, $T$. annae and $B$. gibsoni infection, and blood smears cannot distinguish between T. annae and B. gibsoni. Indeed, the latter technique is also unable to discriminate $B$. canis which, though 


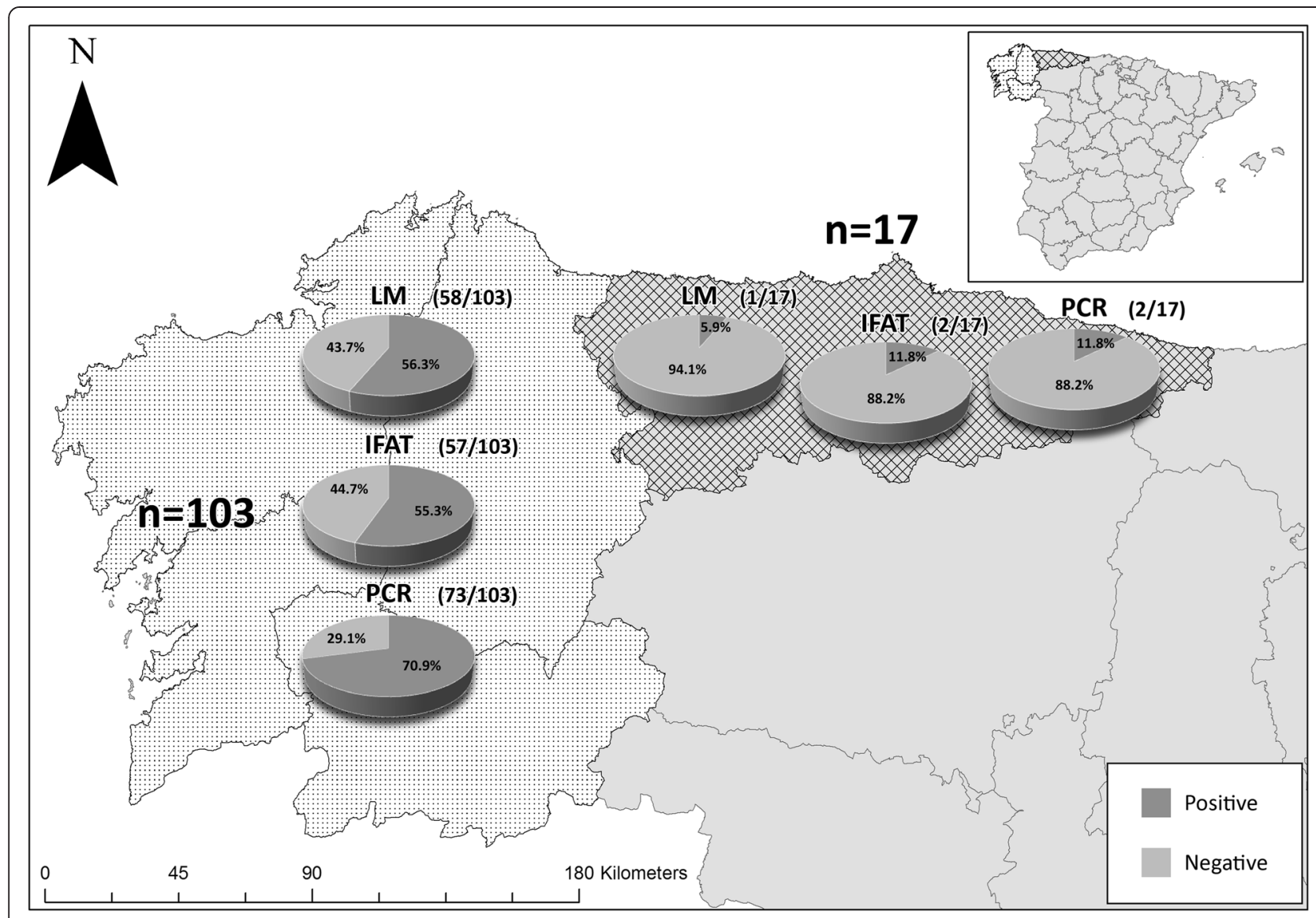

Figure 3 Results obtained using each diagnostic method by study area.

considered a large Babesia, can appear as having pleomorphic intermediate-sized intraerythrocyte stages.

In the current study, PCR and sequencing using universal primer sets specific for piroplasmida enabled the detection of a larger number of animals harbouring T. annae, compared to the other techniques (Figure 1). However, our study failed to clarify the taxonomy of $T$. annae such that more work is needed to resolve this well recognized systematics conundrum [7].

The possibility of co-infections should also be considered. In the north of Spain, summers are warm, winters cool and rainfall is evenly distributed all year round. Accordingly to that, Rhipicephalus sanguineus and Phlebotomus perniciosus, vectors frequently reported in Spain, are uncommon in this region and the prevalences of L. infantum and E. canis are lower than in the rest of Spain. The seroprevalence of $L$. infantum recorded in our study (10.8\%) was higher than previously reported for NW Spain $(3.7 \%$ and 4.1\%) $[49,50]$. This discrepancy could be attributed to the sick population selected for our study rather than a cross-sectional population. An exemption might be the Orense province in NW Spain, where a prevalence of $35.6 \%$ has been observed, similar to that reported in endemic areas of Spain [50]. This prevalence was attributed by the authors to the bioclimatic characteristics of this geographical area. Moreover, in this latter region, the presence of the sandfly, P. perniciosus was also detected. Only one dog from Ourense, which tested negative for $L$. infantum, was enrolled in this study. Twelve of the dogs examined here showed coinfection with piroplasms (T. annae, B. canis or B. gibsoni) and L. infantum. The findings are similar to those in a previous study that showed high co-infection rate of L. infantum in the Babesia positive dogs from Portugal [9]. No E. canis antibodies were detected in our study, coinciding with the low seroprevalence (1.4\%) reported for this infection in NW Spain [30].

With respect to the clinical picture, the most common clinical signs observed in the dogs included in our study were weakness, pale mucous membranes, haemoglobinuria, tachycardia, hyperthermia, tachypnea, and hepatosplenomegaly. These signs consistent with those reported previously for T. annae [25] and Babesia spp. infection [51] were to be expected because many were responsible for a clinical suspicion of piroplasmosis and were thus criteria for inclusion in our study. We observed orangey faeces in $12.5 \%$ of the infected dogs, probably due to high levels of excreted bilirubin. 
Table 5 Epidemiological data recorded in 75 dogs infected with $T$. annae confirmed by PCR and sequencing

\begin{tabular}{|c|c|c|c|}
\hline Variable & & $\mathrm{N}^{\circ}$ total dogs & $\begin{array}{l}\mathrm{N}^{\circ} \text { positive } \\
\text { T. annae dog (\%) }\end{array}$ \\
\hline \multirow[t]{3}{*}{ Age (years) } & $\leq 3$ & 65 & $53(81.54)^{* *}$ \\
\hline & $>3$ & 47 & $22(46.81)$ \\
\hline & unknown & 8 & 0 \\
\hline \multirow[t]{3}{*}{ Sex } & Male & 58 & $38(65.5)$ \\
\hline & Female & 55 & $37(67.2)$ \\
\hline & unknown & 7 & 0 \\
\hline \multirow[t]{3}{*}{ Size (kg) } & $\leq 22$ & 77 & $59(76.6)^{*}$ \\
\hline & $>22$ & 35 & $16(45.71)$ \\
\hline & unknown & 8 & 0 \\
\hline \multirow[t]{3}{*}{ Breed } & Pure breed & 86 & $53(61.6)$ \\
\hline & Crossbreed & 33 & $22(66.6)$ \\
\hline & unknown & 1 & 0 \\
\hline \multirow[t]{4}{*}{ Lifestyle } & Hunting & 75 & $56(74.6)^{*}$ \\
\hline & Companion & 28 & $13(46.4)$ \\
\hline & Guard & 12 & $6(50)$ \\
\hline & unknown & 5 & 0 \\
\hline \multirow[t]{2}{*}{ Habitat } & Rural & 96 & 64 (66.6) \\
\hline & Urban & 24 & $11(45.8)$ \\
\hline \multirow[t]{3}{*}{ Tick infestation } & Yes & 50 & $35(70)$ \\
\hline & No & 49 & $27(55.1)$ \\
\hline & unknown & 21 & $13(10.8)$ \\
\hline \multirow[t]{4}{*}{ Seasonality } & spring & 20 & $14(70)$ \\
\hline & summer & 20 & $10(50)$ \\
\hline & autumn & 60 & 38 (63.3) \\
\hline & winter & 20 & $13(65)$ \\
\hline
\end{tabular}

${ }^{* *} p \leq 0.0001 ;{ }^{*} p \leq 0.02$.

Severe regenerative anaemia and thrombocytopenia were the main haematological findings observed, consistent with prior reports [13]. Regenerative anaemia was typically macrocytic/hypochromic with increased numbers of reticulocytes observed that were relatively larger than mature red blood cells. Reticulocytes are hypochromic because they have not completed haemoglobin synthesis. These haematological abnormalities have been also described by others in T. annae infected dogs in NW Spain [25].

The red blood cell counts, haematocrits and haemoglobin levels recorded in the present animals with suspected piroplasmosis are in agreement with those reported for $62 \mathrm{~T}$. annae -infected dogs examined in 2003, $90 \%$ of which showed values lower than $4.46 \times 10^{6}$ erythrocytes $/ \mu \mathrm{L}$, $10.52 \mathrm{~g}$ haemoglobin/dL and $31.04 \%$ haematocrit [13]. Leukocyte abnormalities have been inconsistently observed in dogs with piroplasmosis [25]. Total leukocyte counts were greater than $17 \times 10^{3}$ cells $/ \mu \mathrm{L}$ in $25 \%$ of the animals examined here, and there was a trend towards neutrophilia and eosinopenia. This could be a consequence of the severe stress associated with this illness, in line with observations by other authors [13].

We only detected a few cases of azotaemia (9.8\%) despite others observing its high prevalence in this disease $(36 \%)[13,52]$ and suggesting its strong correlation with the likelihood of death within the first week of diagnosis [52]. High ALP activity was observed in $43.8 \%$ of the infected dogs despite reports of liver disease only in other types of piroplasmosis [53].

Our epidemiological results are in agreement with observations by García et al. [13], who mentioned that the age distribution of their study population reflected a greater risk of infection in younger animals [13]. Frequencies of infection by Babesia species in endemic areas have been described as inversely proportional to animal age. The correlation observed here, between an animal weight under $22 \mathrm{~kg}$ or a hunting type dog and a greater likelihood of $T$. annae infection, could reflect the fact that hunting dogs are usually fairly light. A large number of the T. annae infected dogs included in our study lived in rural areas and were infested by ticks. Other authors have reported a greater risk of $T$. annae infection in hunting dogs or dogs infested by ticks [25,54]. As also noted for other Babesia species [54,55], we observed no correlation between $T$. annae infection and sex or breed. García et al. [13] reported that autumn and winter were the periods when most cases of $T$. annae were observed. However, we observed no significant correlation between season and T. annae infection.

By PCR and sequencing, we detected three positive cases of B. gibsoni infection among the 120 dogs with suspected piroplasmosis. However, we have insufficient data to confirm the autochthonous nature of these cases. B. gibsoni has been sporadically reported in dogs travelling to endemic areas $[10,14]$ and more epidemiological studies are needed to evaluate its presence in Spain. In contrast, $B$. canis has been often identified in dogs in northern Spain and Portugal [56] and both its diagnosis and clinical management by veterinarians in these regions are effective [8]. Despite not being included in our study, among dogs diagnosed in the participating clinics as having piroplasmosis caused by B. canis, 12 cases proved PCR positive. This could reflect the high prevalence of B. canis in NW Spain and its similar clinical signs to $T$. annae infection. Moreover, the pleomorphic nature of $B$. canis hinders its microscopy identification and a molecular confirmation is often required on which to base selection of the best treatment option. One of the two PCR-confirmed cases in Asturias (outside Galicia) had never left that area, suggesting that $T$. annae infection could be spreading to neighbouring regions. This idea requires confirmation in future studies. 


\section{Conclusions}

Currently, microscopy detection of the parasite is the most simple and rapid diagnostic method, provided it is performed by a specialized technician. This procedure shows a moderate sensitivity for the pathogen in the acute infection stage when IFAT-determined antibody titres are low. However, sensitivity increases when IFAT and LM are used together. PCR is able to detect a larger number of positive cases and confirm the species involved. For an accurate diagnosis, we would recommend an integrative approach based on epidemiological evidence, the clinical picture, LM and/or IFAT, and confirmation of the infecting species by a molecular method. We propose that the decision tree in Figure 1 may be useful for clinically managing $T$. annae infection in endemic regions or in dogs travelling to an endemic area. With regards to the possibility that this small piroplasm could spread across northern Spain, we fear that bordering areas of Galicia with similar climate conditions could be already affected. This concern determines a need for larger epidemiological surveys in which molecular and serological methods are used to detect dogs with chronic or subclinical infection. The data emerging from such studies will serve to more reliably establish the current prevalence of $T$. annae infection in northern mainland Spain. Finally, our study does not clarify the systematics of $T$. annae such that we recommend more work in this area.

\section{Competing interests}

The authors declare they have no competing interests.

\section{Authors' contributions}

GM conceived and coordinated the study, participated in its design and the field study, and drafted and finalized the manuscript. RC processed the blood samples and carried out the serological and microscopy procedures, performed the statistical analysis of data, and drafted and reviewed the final manuscript. AM participated in the diagnostic assays, helped with the statistical analysis of data and reviewed the final manuscript. RG helped with the laboratory work, data collection and manuscript draft. NO participated in the field study and the veterinarian enrolment procedures. JLG, AB and PPM helped with the clinical cases enrolment and blood sample collection. AP and AG participated in the molecular assays and AP helped with editing of the manuscript. PI participated in the study design, and drafted and finalized the manuscript. All authors read and approved the final manuscript.
\end{abstract}

\section{Acknowledgements}

The authors thank the participating practitioners for giving us access to the clinical cases included in this study. We also thank Dr. Ángel Tomás Camacho García for his advice and expertise on diagnosing T. annae infection, Prof. Gad Baneth for his help with the molecular diagnosis of the first clinical cases, and Dr. Laia Solano-Gallego for her expert advice on canine piroplasmosis.

This study was partially funded by grant AGL2011-29862 awarded by the Spanish Ministry of Economy and Finance.

Publication of the CVBD10 thematic series was sponsored by Bayer Animal Health $\mathrm{GmbH}$.

\section{Author details}

${ }^{1}$ Department of Animal Health, Veterinary Faculty, Universidad Complutense de Madrid, Madrid, Spain. ${ }^{2}$ Vector- and Water-Borne Pathogen Research Group, School of Veterinary \& Life Sciences, Murdoch University, Murdoch,
WA, Australia. ${ }^{3}$ Xarope Veterinary Centre, Laracha, Coruña, Spain. ${ }^{4}$ Gran Vía Veterinary Centre, Carballo, Coruña, Spain. ${ }^{5}$ Hospital Veterinario Nacho Menes, Gijón, Asturias, Spain.

Received: 3 February 2015 Accepted: 23 March 2015

Published online: 10 April 2015

\section{References}

1. Irwin PJ. Canine babesiosis. Vet Clin North Am Small Anim Pract. 2010;40(6):1141-56.

2. Zahler M, Rinder $\mathrm{H}$, Schein $\mathrm{E}$, Gothe R. Detection of a new pathogenic Babesia microti-like species in dogs. Vet Parasitol. 2000;89(3):241-8.

3. Boozer AL, Macintire DK. Canine babesiosis. Vet Clin North Am Small Anim Pract. 2003;33(4):885-904. viii.

4. Irwin PJ. Canine babesiosis: from molecular taxonomy to control. Parasit Vectors. 2009;2 Suppl 1:S4.

5. Camacho AT, Pallas E, Gestal JJ, Guitian FJ, Olmeda AS, Goethert HK, et al. Infection of dogs in north-west Spain with a Babesia microti-like agent. Vet Rec. 2001;149(18):552-5.

6. Criado-Fornelio A, Martinez-Marcos A, Buling-Saraña A, Barba-Carretero JC. Molecular studies on Babesia, Theileria and Hepatozoon in southern Europe. Part II. Phylogenetic analysis and evolutionary history. Vet Parasitol. 2003;114(3):173-94.

7. Goethert HK, Telford SR. What is Babesia microti? Parasitology. 2003;127(Pt 4):301-9.

8. Solano-Gallego L, Baneth G. Babesiosis in dogs and cats-expanding parasitological and clinical spectra. Vet Parasitol. 2011;181(1):48-60.

9. Yisaschar-Mekuzas Y, Jaffe CL, Pastor J, Cardoso L, Baneth G. Identification of Babesia species infecting dogs using reverse line blot hybridization for six canine piroplasms, and evaluation of co-infection by other vector-borne pathogens. Vet Parasitol. 2013;191(3-4):367-73.

10. Criado-Fornelio A, Gónzalez-del-Río MA, Buling-Saraña A, Barba-Carretero JC. Molecular characterization of a Babesia gibsoni isolate from a Spanish dog. Vet Parasitol. 2003;117(1-2):123-9.

11. Jefferies R, Ryan UM, Jardine J, Broughton DK, Robertson ID, Irwin PJ. Blood, Bull Terriers and Babesiosis: further evidence for direct transmission of Babesia gibsoni in dogs. Aust Vet J. 2007:85(11):459-63.

12. Yeagley TJ, Reichard MV, Hempstead JE, Allen KE, Parsons LM, White MA, et al. Detection of Babesia gibsoni and the canine small Babesia 'Spanish isolate' in blood samples obtained from dogs confiscated from dogfighting operations. J Am Vet Med Assoc. 2009;235(5):535-9.

13. Garcia AT. Piroplasma infection in dogs in northern Spain. Vet Parasitol. 2006;138(1-2):97-102.

14. Tabar MD, Francino O, Altet L, Sánchez A, Ferrer L, Roura X. PCR survey of vectorborne pathogens in dogs living in and around Barcelona, an area endemic for leishmaniasis. Vet Rec. 2009;164(4):112-6.

15. Simões PB, Cardoso L, Araújo M, Yisaschar-Mekuzas Y, Baneth G. Babesiosis due to the canine Babesia microti-like small piroplasm in dogs-first report from Portugal and possible vertical transmission. Parasit Vectors. 2011;4:50.

16. Beck R, Vojta L, Mrljak V, Marinculić A, Beck A, Zivicnjak T, et al. Diversity of Babesia and Theileria species in symptomatic and asymptomatic dogs in Croatia. Int J Parasitol. 2009;39(7):843-8.

17. Falkenö U, Tasker S, Osterman-Lind E, Tvedten HW. Theileria annae in a young Swedish dog. Acta Vet Scand. 2013;55:50.

18. Lledó L, Giménez-Pardo C, Domínguez-Peñafiel G, Sousa R, Gegúndez MI, Casado N, et al. Molecular detection of hemoprotozoa and Rickettsia species in arthropods collected from wild animals in the Burgos Province, Spain. Vector Borne Zoonotic Dis. 2010;10(8):735-8.

19. Cardoso L, Cortes HC, Reis A, Rodrigues P, Simões M, Lopes AP, et al. Prevalence of Babesia microti-like infection in red foxes (Vulpes vulpes) from Portugal. Vet Parasitol. 2013;196(1-2):90-5.

20. Zanet S, Trisciuoglio A, Bottero E, de Mera IG, Gortazar C, Carpignano MG, et al. Piroplasmosis in wildlife: Babesia and Theileria affecting free-ranging ungulates and carnivores in the Italian Alps. Parasit Vectors. 2014;7:70.

21. Dezdek D, Vojta L, Curković S, Lipej Z, Mihaljević Z, Cvetnić Z, et al. Molecular detection of Theileria annae and Hepatozoon canis in foxes (Vulpes vulpes) in Croatia. Vet Parasitol. 2010;172(3-4):333-6.

22. Clancey N, Horney B, Burton S, Birkenheuer A, McBurney S, Tefft K. Babesia (Theileria) annae in a red fox (Vulpes vulpes) from Prince Edward Island, Canada. J Wildl Dis. 2010;46(2):615-21. 
23. Birkenheuer AJ, Horney B, Bailey M, Scott M, Sherbert B, Catto V, et al. Babesia microti-like infections are prevalent in North American foxes. Vet Parasitol. 2010;172(3-4):179-82.

24. Camacho AT, Pallas E, Gestal JJ, Guitian FJ, Olmeda AS, Telford SR, et al. Ixodes hexagonus is the main candidate as vector of Theileria annae in northwest Spain. Vet Parasitol. 2003:112(1-2):157-63.

25. Guitian FJ, Camacho AT, Telford 3rd SR. Case-control study of canine infection by a newly recognised Babesia microti-like piroplasm. Prev Vet Med. 2003;61(2):137-45.

26. Dantas-Torres F, Figueredo LA. Canine babesiosis: a Brazilian perspective. Vet Parasitol. 2006;141(3-4):197-203.

27. Birkenheuer AJ, Levy MG, Stebbins M, Poore M, Breitschwerdt E. Serosurvey of antiBabesia antibodies in stray dogs and American pit bull terriers and American staffordshire terriers from North Carolina. J Am Anim Hosp Assoc. 2003;39(6):551-7.

28. Jefferies R, Ryan UM, Irwin PJ. PCR-RFLP for the detection and differentiation of the canine piroplasm species and its use with filter paper-based technologies. Vet Parasitol. 2007;144(1-2):20-7.

29. Birkenheuer AJ, Levy MG, Breitschwerdt EB. Development and evaluation of a seminested PCR for detection and differentiation of Babesia gibsoni (Asian genotype) and B. canis DNA in canine blood samples. J Clin Microbiol. 2003;41(9):4172-7.

30. Miró G, Montoya A, Roura X, Gálvez R, Sainz A. Seropositivity rates for agents of canine vector-borne diseases in Spain: a multicentre study. Parasit Vectors. 2013;6:117.

31. Mancianti F, Meciani N. Specific serodiagnosis of canine leishmaniasis by indirect immunofluorescence, indirect hemagglutination, and counter immunoelectrophoresis. Am J Vet Res. 1988;49(8):1409-11.

32. Katoh K, Misawa K, Kuma K, Miyata T. MAFFT: a novel method for rapid multiple sequence alignment based on fast Fourier transform. Nucleic Acids Res. 2002;30(14):3059-66.

33. Edgar RC. MUSCLE: a multiple sequence alignment method with reduced time and space complexity. BMC Bioinformatics. 2004;5:113.

34. Price MN, Dehal PS, Arkin AP. FastTree 2-approximately maximum-likelihood trees for large alignments. PLoS One. 2010;5(3):e9490

35. Castresana J. Selection of conserved blocks from multiple alignments for their use in phylogenetic analysis. Mol Biol Evol. 2000;17(4):540-52.

36. Dereeper A, Guignon V, Blanc G, Audic S, Buffet S, Chevenet F, et al. Phylogeny.fr: robust phylogenetic analysis for the non-specialist. Nucleic Acids Res. 2008:36(Web Server issue):W465-9.

37. Schnittger $L$, Rodriguez AE, Florin-Christensen M, Morrison DA. Babesia: a world emerging. Infect Genet Evol. 2012;12(8):1788-809.

38. Estrada-Peña A, Bouattour A, Camicas JL, Walker AR. Ticks of domestic animals in the Mediterranean Region. A guide to identification of species. Spain: University of Zaragoza; 2004. p. 131

39. Tani H, Tada Y, Sasai K, Baba E. Improvement of DNA extraction method for dried blood spots and comparison of four PCR methods for detection of Babesia gibsoni (Asian genotype) infection in canine blood samples. J Vet Med Sci. 2008;70(5):461-7.

40. Abutarbush SM, Alqawasmeh DM, Mukbel RM, Al-Majali AM. Equine babesiosis: seroprevalence, risk factors and comparison of different diagnostic methods in Jordan. Transbound Emerg Dis. 2012;59(1):72-8.

41. Fukumoto S, Xuan X, Shigeno S, Kimbita E, Igarashi I, Nagasawa H, et al. Development of a polymerase chain reaction method for diagnosing Babesia gibsoni infection in dogs. J Vet Med Sci. 2001;63(9):977-81.

42. Fukumoto $S$, Sekine $Y$, Xuan $X$, Igarashi I, Sugimoto C, Nagasawa $H$, et al. Serodiagnosis of canine Babesia gibsoni infection by enzyme-linked immunosorbent assay with recombinant P50 expressed in Escherichia coli. J Parasitol. 2004:90(2):387-91.

43. Navarro C, Reymond N, Fourie J, Hellmann K, Bonneau S. Prevention of Babesia canis in dogs: efficacy of a fixed combination of permethrin and fipronil (Effitix ${ }^{\circledast}$ ) using an experimental transmission blocking model with infected Dermacentor reticulatus ticks. Parasit Vectors. 2015;8(1):32.

44. Kubelová M, Sedlák K, Panev A, Široký P. Conflicting results of serological, PCR and microscopic methods clarify the various risk levels of canine babesiosis in Slovakia: a complex approach to Babesia canis diagnostics. Vet Parasitol. 2013;191(3-4):353-7.

45. Yamane I, Thomford JW, Gardner IA, Dubey JP, Levy M, Conrad PA. Evaluation of the indirect fluorescent antibody test for diagnosis of Babesia gibsoni infections in dogs. Am J Vet Res. 1993;54(10):1579-84
46. Goo YK, Jia H, Aboge GO, Terkawi MA, Kuriki K, Nakamura C, et al. Babesia gibsoni: Serodiagnosis of infection in dogs by an enzyme-linked immunosorbent assay with recombinant BgTRAP. Exp Parasitol. 2008;118(4):555-60.

47. Vercammen F, De Deken $R$, Maes L. Duration of protective immunity in experimental canine babesiosis after homologous and heterologous challenge. Vet Parasitol. 1997;68(1-2):51-5.

48. Maggi RG, Birkenheuer AJ, Hegarty BC, Bradley JM, Levy MG, Breitschwerdt EB. Comparison of serological and molecular panels for diagnosis of vectorborne diseases in dogs. Parasit Vectors. 2014;7:127.

49. Amusátegui I, Sainz A, Aguirre E, Tesouro MA. Seroprevalence of Leishmania infantum in northwestern Spain, an area traditionally considered free of leishmaniasis. Ann N Y Acad Sci. 2004;1026:154-7.

50. Miró G, Checa R, Montoya A, Hernández L, Dado D, Gálvez R. Current situation of Leishmania infantum infection in shelter dogs in northern Spain. Parasit Vectors. 2012;5:60.

51. Salem NY, Farag HS. Clinical, Hematologic, and Molecular Findings in Naturally Occurring Babesia canis vogeli in Egyptian Dogs. Vet Med Int. 2014;2014:270345

52. Camacho AT, Guitian EJ, Pallas E, Gestal JJ, Olmeda AS, Goethert HK, et al. Azotemia and mortality among Babesia microti-like infected dogs. J Vet Intern Med. 2004;18(2):141-6.

53. Wozniak EJ, Barr BC, Thomford JW, Yamane I, McDonough SP, Moore PF, et al. Clinical, anatomic, and immunopathologic characterization of Babesia gibsoni infection in the domestic dog (Canis familiaris). J Parasitol. 1997;83(4):692-9.

54. Imre M, Farkas R, Ilie M, Imre K, Hotea I, Morariu S, et al. Seroprevalence of Babesia canis infection in clinically healthy dogs from western Romania. J Parasitol. 2013:99(1):161-3.

55. Singh A, Singh $H$, Singh NK, Singh ND, Rath SS. Canine babesiosis in northwestern India: molecular detection and assessment of risk factors. Biomed Res Int. 2014:2014:741785.

56. Cardoso L, Yisaschar-Mekuzas Y, Rodrigues FT, Costa A, Machado J, Diz-Lopes D, et al. Canine babesiosis in northern Portugal and molecular characterization of vector-borne co-infections. Parasit Vectors. 2010;3(1):27.

\section{Submit your next manuscript to BioMed Central and take full advantage of:}

- Convenient online submission

- Thorough peer review

- No space constraints or color figure charges

- Immediate publication on acceptance

- Inclusion in PubMed, CAS, Scopus and Google Scholar

- Research which is freely available for redistribution 